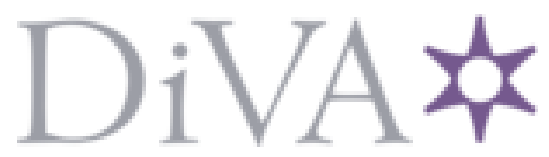

http://www.diva-portal.org

\title{
Preprint
}

This is the submitted version of a paper published in Infrared physics \& technology.

Citation for the original published paper (version of record):

Haglund, J., Jeppsson, F., Melander, E., Pendrill, A-M., Xie, C. et al. (2016)

Infrared cameras in science education.

Infrared physics \& technology, 75(March): 150-152

http://dx.doi.org/10.1016/j.infrared.2015.12.009

Access to the published version may require subscription.

N.B. When citing this work, cite the original published paper.

Permanent link to this version:

http://urn.kb.se/resolve?urn=urn:nbn:se:uu:diva-276317 


\section{Infrared Cameras in Science Education}

Authors: Jesper Haglund ${ }^{1 *}$, Fredrik Jeppsson ${ }^{2}$, Emil Melander ${ }^{1}$, Ann-Marie Pendrill ${ }^{3}$, Charles $\mathrm{Xie}^{4}$, Konrad J. Schönborn ${ }^{5}$

\section{Affiliations:}

${ }^{1}$ Department of Physics and Astronomy, Uppsala University, Box 516, 75120 Uppsala, Sweden. Email address: jesper.haglund@physics.uu.se

${ }^{2}$ Department of Social and Welfare Studies, Linköping University, 60174 Norrköping, Sweden. Email address: fredrik.jeppsson@liu.se

${ }^{3}$ The Swedish National Resource Centre for Physics Education, Lund University, Box 118, 22100 Lund, Sweden. Email address: ann-marie.pendrill@fysik.lu.se

${ }^{4}$ The Concord Consortium, 25 Love Lane, Concord, MA 01742, USA. Email address: qxie@concord.org

${ }^{5}$ Department of Science and Technology, Linköping University, 60174 Norrköping, Sweden. Email address: konrad.schonborn@liu.se

* Corresponding author

This is a preprint version of the accepted article.

Haglund, J., Jeppsson, F., Melander, E., Pendrill, A.-M., Xie, C., \& Schönborn, K. J. (2016). Infrared cameras in science education. Infrared Physics \& Technology, 75(March), 150-152. doi: http://dx.doi.org/10.1016/j.infrared.2015.12.009 


\section{Infrared Cameras in Science Education}

Infrared (IR) thermography has numerous industrial, medical, and research applications. This article describes its applications in the science classroom. By visualizing invisible phenomena, real-time thermal imaging can be exploited to teach a wide range of science topics [1] that deal with energy transfers representing physical and chemical processes. Thermal imaging opens a new, exciting frontier of visualization in science education [2]. In this article, we present qualitative educational research on thermal imaging applications and laboratory activities that have been developed and implemented in areas of science education across primary, secondary, higher, and informal settings.

\section{Infrared cameras enhance laboratory learning in undergraduate physics and chemistry education}

Thermal imaging can be used to gather quantitative data for students' exploration of physical phenomena, such as thermal diffusion from a point source [3], cooling of roller-coaster brakes [4], or in the development of an analogy between thermal and electrical conduction [5]. In this manner, IR cameras have been introduced in thermal engineering to study various modes of heat transfer [6].

As an easy-to-use, yet powerful, technology, thermal imaging is particularly well suited for inquiry-based laboratory activities [7] in physics and chemistry education [8,9]. To demonstrate the versatility of this technique, a series of IR-camera experiments have been developed and shared [10].

Physics and engineering students took part in open-ended laboratory experiments in thermodynamics using IR cameras to investigate thermal conduction, convection and radiation, as well as the function of technical apparatus such as a heat pump [11] (Fig. 1). With the help of IR cameras (FLIR E6 and C2), students discovered that IR radiation reflects more than visual light on shiny surfaces such as glass windows or whiteboards, and that metal surfaces painted black and white have a comparable emissivity in the IR range, where they both counterintuitively - can be considered as 'black bodies'.

\section{Infrared cameras accelerate inquiry in primary and secondary education}

Thirty years ago, in relation to the phenomenon that metals feel cold at room temperature, Gaalen Erickson [12] (p. 59) presaged: "If pupils were able to 'see' this phenomenon in terms of a transfer of energy from their body to the object, this sort of situation would likely be less of a problem than it seems to be at present." Thirty years later, pupils can actually see heat conduction from their hands to a colder object through an IR camera (Fig. 2).

In a four-year research program focused on investigating how thermal imaging can support science learning in primary and secondary schools, a suite of IR-camera-based laboratory activities have been developed to target the Swedish grade 4-12 physics curricula $[13,14,15,16]$. The activities build on the widely-adopted predict-observe-explain (POE) approach [17], where students are asked to predict what will happen in an experiment, carefully observe as the experiment unfolds, and then explain what they observed and reconcile their observations with their predictions when there is a discrepancy.

In a pilot study that aimed to confront the erroneous idea that metals are inherently colder than other substances, pairs of grade-7 (12 to 13-years-old) students investigated the temperatures of 
wood and metal objects at room temperature [16]. Rather than making full use of the dynamic colour images and attend to the theory of heat transfer as an explanation, the students instead used the IR cameras to read temperatures. This was attributed to the lack of a conceptual model for understanding heat transfer [18]. Subsequently, two grade-4 classes (9 to 10-year-olds) were introduced to such a heat transfer model. They conducted a series of IR-camera experiments, including the wood vs. metal task and the pouring of hot water into cups with different wall thicknesses and materials [14] (Fig. 3). The grade-4 pupils were able to adopt the heat transfer model. They were also engaged in "instant inquiry" in asking "what-if" questions and exploring the questions with the IR cameras. For example, they wondered about what would happen if they blew on the hot water surface or immersed an object into the water. In a separate study, groups of upper-secondary students (17 to 18-year-olds) carried out IR experiments to study heat conduction, friction, (e.g. rubbing an eraser on the surface of a table) and inelastic collisions (e.g. observing the heating due to the impact of a metal ball falling to the floor, Fig. 4) [13]. We found that higher-level students tended to invoke microscopic models in their explanations of the phenomena.

\section{Infrared cameras inspire creative investigation of thermal phenomena at science museums}

Thermal imaging has been used in informal settings, such as science museum exhibits [19]. In comparison with being asked to follow detailed instructions, visitors have been found to engage more creatively with the technology through minimal guidance, such as observing melting snow brought in from outside or visualizing temperature increase from rubbing their hands together.

\section{Opportunities and implications}

As the price has dropped significantly in recent years, IR cameras have become an attractive educational technology for science education, which complements traditional thermometer measurements. Although our work shows that learners can develop thermal concepts through IR imaging, students still need to be prepared with age-appropriate scientific models of the studied phenomena, such as a simple model of heat conduction [18], in order to be able to interpret what they see through an IR camera. While IR imaging provides a way to visualize thermal phenomena at the macroscopic level, it can be complemented with other visualization tools such as the Molecular Workbench [20] to teach microscopic concepts.

Our research has provided evidence that use of IR cameras in conjunction with relatively simple, yet conceptually powerful activities can inspire students of all ages to inquire about thermal phenomena and support the development of conceptual understanding in thermodynamics.

\section{References}

[1] M. Vollmer, K.-P. Möllmann, F. Pinno, \& D. Karstädt. There is more to see than eyes can detect Visualization of energy transfer processes and the laws of radiation for physics education. Phys. Teach. 39 (6) (2001). 371-376.

[2] J.K. Gilbert (Ed.) Visualization in science education. Springer, Dordrecht, the Netherlands, 2005.

[3] T. Gfroerer, R. Phillips, \& P. Rossi. Thermal diffusivity imaging. Am. J. Phys. 83 (11) (2015). $923-927$.

[4] A.-M. Pendrill, M. Karlsteen, \& H. Rödjegård. Stopping a roller coaster train. Phys. Educ. 47 (6) (2012). 728-735.

[5] O. Stefano, \& Z. Giuliano. Electro-thermal analogies and imaging radiation thermometry. Eur. J. Phys. 36 (6) (2015). 065016.

[6] R. Cabello, J. Navarro-Esbrí, R. Llopis, \& E. Torrella. Infrared thermography as a useful tool to improve learning in heat transfer related subjects. Int. J. Eng. Educ. 22 (2) (2006). 373-380.

[7] A. Hofstein, \& V.N. Lunetta. The laboratory in science education: Foundations for the twenty-first century. Sci. Educ. 88 (1) (2004). 28-54. 
[8] C. Xie. Visualizing chemistry with infrared imaging. J. Chem. Educ. 88 (7) (2011). 881-885.

[9] C. Xie, \& E. Hazzard. Infrared imaging for inquiry-based learning. Phys. Teach. 49 (6) (2011). 368-372.

[10] C. Xie. The Concord Consortium. Infrared Tube. Retrieved from http://energy.concord.org/ir, 2014.

[11] E. Melander, J. Haglund, M. Weiszflog, \& S. Andersson. More than meets the eye - infrared cameras in open-ended university thermodynamics labs. (in review).

[12] G.L. Erickson, Heat and temperature. Part A: An overview of pupils' ideas. In: R. Driver, E. Guesne, \& A. Tiberghien (Eds.), Children's ideas in science, Open University Press, Milton Keynes, UK, 1985, pp. 55 66.

[13] J. Haglund, F. Jeppsson, D. Hedberg, \& K.J. Schönborn. Students' framing of laboratory exercises using infrared cameras. Phys. Rev. ST Phys. Educ. Res. 11 (2) (2015). 020127.

[14] J. Haglund, F. Jeppsson, \& K. Schönborn. Taking on the heat - a narrative account of how infrared cameras invite instant inquiry. Res. Sci. Educ. (2015). doi:10.1007/s11165-015-9476-8

[15] J. Haglund, F. Jeppsson, D. Hedberg, \& K.J. Schönborn. Thermal cameras in school laboratory activities. Phys. Educ. 50 (4) (2015). 424-430.

[16] K.J. Schönborn, J. Haglund, \& C. Xie. Pupils' early explorations of thermoimaging to interpret heat and temperature. J. Balt. Sci. Educ. 13 (1) (2014). 118-132.

[17] R. White, \& R. Gunstone, Probing understanding. The Falmer Press, London, UK, 1992.

[18] M.C. Linn, \& B.-S. Eylon, Science learning and instruction: taking advantage of technology to promote knowledge integration. Routledge, New York, NY, 2011.

[19] L.J. Atkins, L. Velez, D. Goudy, \& K. Dunbar. The unintended effects of interactive objects and labels in the science museum. Sci. Educ. 93 (1) (2009). 161-184.

[20] C. Xie, R. Tinker, B. Tinker, A. Pallant, D. Damelin, \& B. Berenfeld. Computational experiments for science education. Science 332 (6037) (2011). 1516-1517.

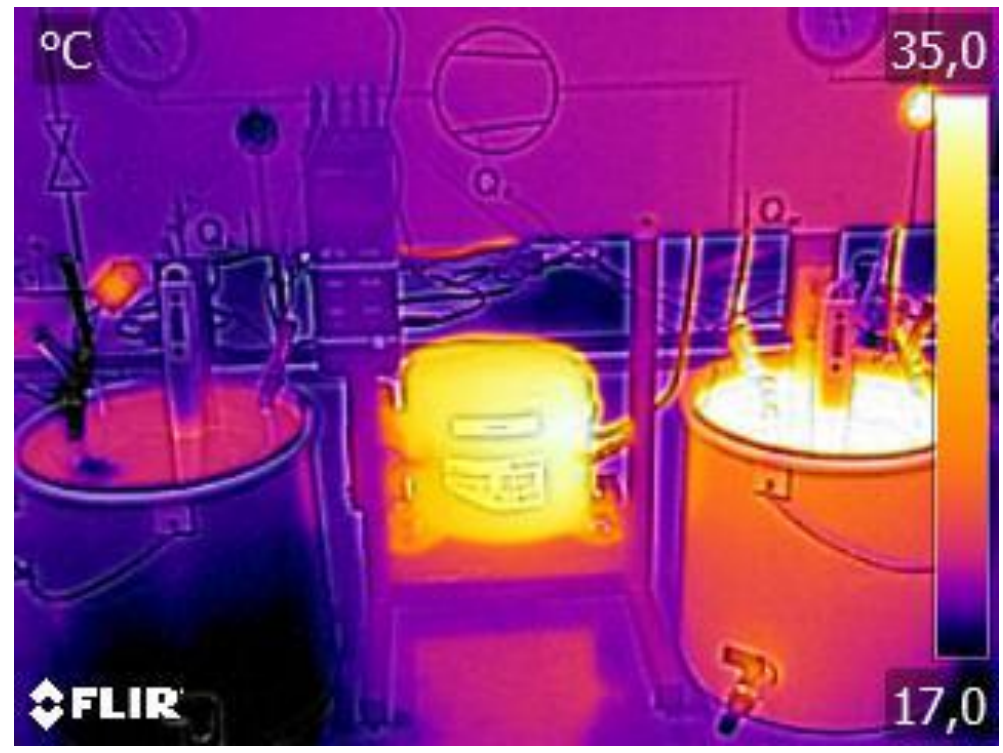

Fig 1. With the aid of an IR camera, students can easily discern the components of a heat pump. 


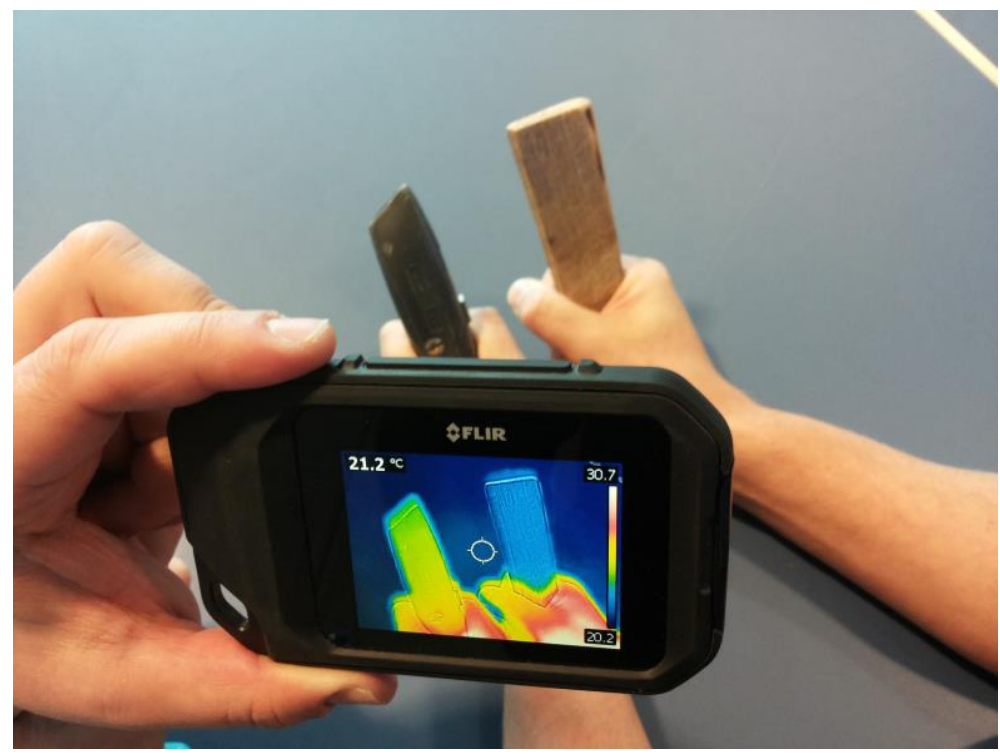

Fig 2. Students can investigate heat conduction between their bodies and objects of different materials, such as wood (a good insulator) and metal (a good conductor) with an IR camera.

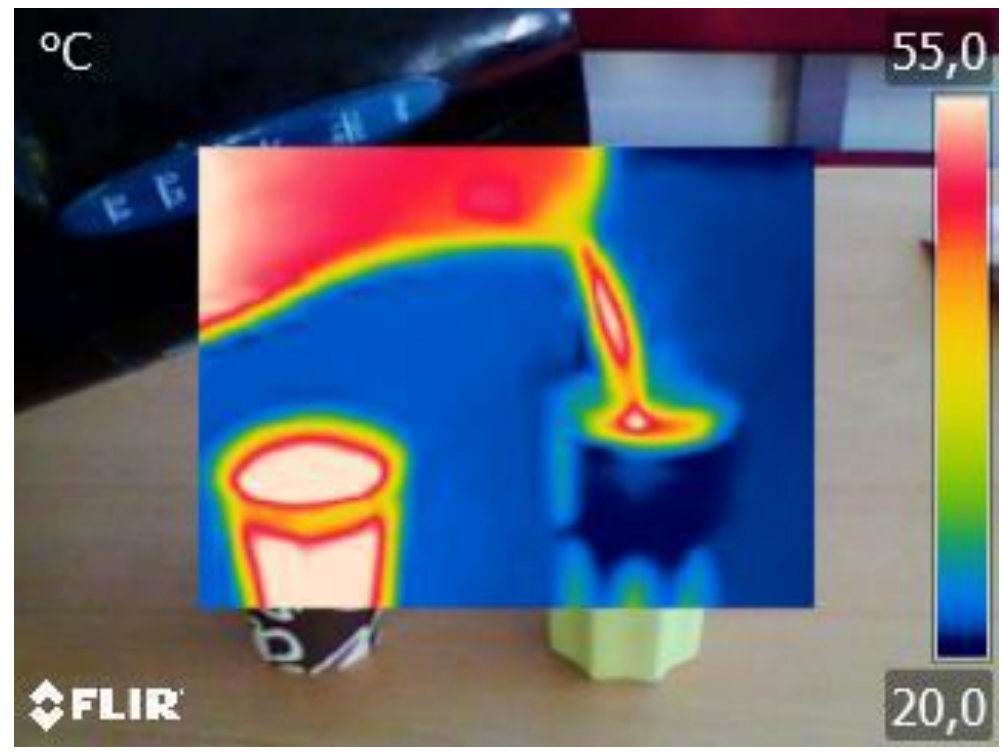

Fig 3. Overlay IR image of hot water being poured into a thick-walled ceramic mug (right). In contrast, a thin-walled paper cup (left) quickly assumes the temperature of the water. 


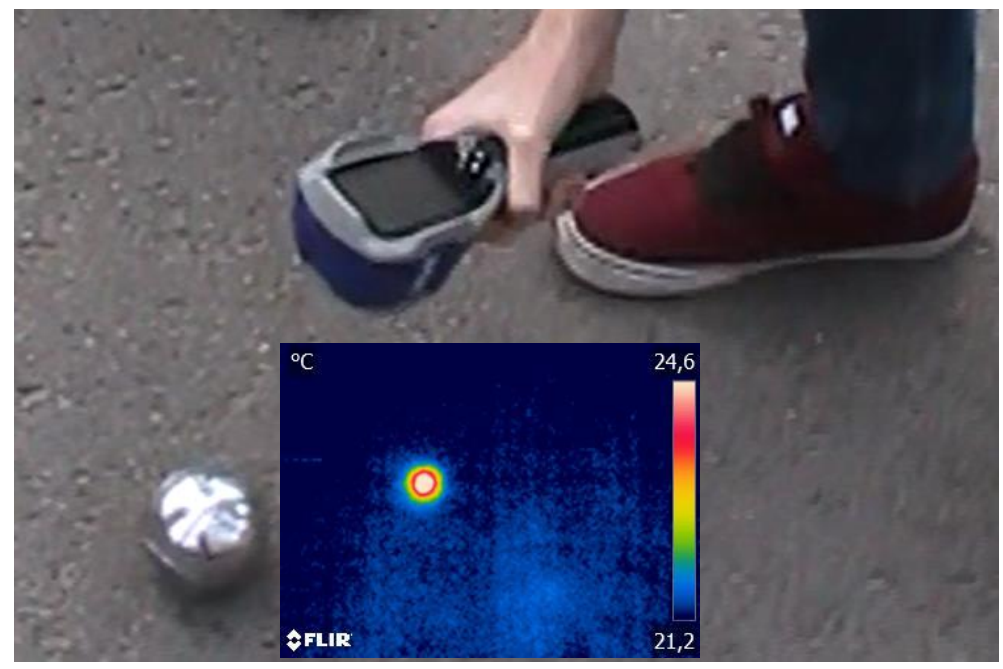

Fig 4. An image demonstrating the increase in temperature of asphalt at the point of collision with a metal ball dropped from a height. The IR inset shows conceptually challenging energy transformation from kinetic to thermal energy. 